\title{
Synthesis of 6H-thiochromeno [3, 4-b] Quinoxaline Derivatives and their Antifungal Activities
}

\author{
Peng Wei \\ Pharmacology School, Hebei University, Baoding 071002 \\ Jingjing Liu \\ Pharmacology School, Hebei University, Baoding 071002 \\ Junjie Ma \\ Pharmacology School, Hebei University, Baoding 071002 \\ Gengliang Yang (Corresponding author) \\ Pharmacology School, Hebei University, Baoding 071002 \\ Tel: 86-312-5079788Ｅ-mail: ygl@mail.hbu.edu.cn
}

\begin{abstract}
Objective: To design to synthesize $6 \mathrm{H}$-thiochromeno [3, 4-b] quinoxaline derivatives and evaluate their antifungal activities.

Methods: The target compounds were prepared from substituted thiophenol by several steps, and separated by column chromatography.

Results: Four new unreported compounds were obtained. All compounds were confirmed by $1 \mathrm{H}$ NMR and MS spectral analysis. Preliminary pharmacological test showed that two compounds both possessed potential antifungal activities.

Conclusion: The synthesized 6H-thiochromeno [3, 4-b] quinoxaline derivatives had certain antifungal activities in some tested fungal strains in vitro.
\end{abstract}

Keywords: Substituted thiophenol, 6H-thiochromeno [3, 4-b] quinoxaline derivative, Antifungal activity

Thiochromanones were a class of heterocyclic compounds with sulfur atom, and possessed a wind range of physiological activities (Nakb, 1990, PP. 455-462). These compounds after inducing substituent in the third position could lead to the increment of antifungal activities significantly (Tramontin, 1990, PP. 1791-1837; Qi, 2004, PP. 141-143; Qi, 2004, PP. 134-137). Quinoxaline compounds were pharmacophores with high biological activities (Li, 2007, PP. 183-187), possessed antitumor, antifungal and other activities, and could be used as an agent to inhibit HIV-1 reverse transcriptase ( $\mathrm{Li}, 2007$, PP. 34-36). In the present paper, we attempted to induce the molecular structure of quinoxaline into the third position of Thiochromanone, and aimed at finding new antifungal drugs with the molecular structure of $6 \mathrm{H}$-thiochromeno [3, 4-b] quinoxaline.

According to the method initiated by Xiao et al (2006, PP. 979-982), the substituted thiophenol used as initial material and $\beta$-arylthioethers were condensed into compound 1 under microwave irradiation. Compound 1 was undertaken catalytic annulation using concentrated sulfuric acid and substituted thiochromanone 2 was obtained. Compound 2 was dissolved in anhydrous with the dropwise addition of bromine, and compound 3 was obtained after reaction. Compound 3 was oxidized by DMSO (Dimethyl supphoxide) and reacted with o-phenylenediamine into target compound 4 through dehydration. Synthetic route was illustrated in Figure 1.

\section{Materials and methods}

\subsection{Instruments and reagents}

Melting point of compounds was determined by Shenguang SGW X-4 micro melting point detector; Microwave generating device was Glanz family microwave oven (G7020 II TL2 with the power of $700 \mathrm{~W}$ ); HNMR was assayed using Bruker AV-III-600MHz NMR spectrometer, TMS used as internal standard and $\mathrm{CDCl}_{3}$ as solvent; mass spectrometry analysis was operated by the Agilent LC/MSD Trap XCT-based LC-MS. Substituted thiophenol was chemically pure, and other reagents were of analytical grade. Control drug amphotericin B was purchased from North China Pharmaceutical Factory, and fluconazole from Shijiazhuang Pharmaceutical Factory. 
10 fungi tested in the antibacterial trial in vitro were purchased from Culture Collection of strains, Chinese Academy of Medical Sciences.

\subsection{Synthetic method of replaced thiochromanone (2)}

$7.1 \mathrm{~g}$ (50mmol) 3-F 4-methyl thiophenol and $6.5 \mathrm{~g}(60 \mathrm{mmol}) \beta$-chloropropionic acid were placed in $250 \mathrm{ml}$ conical flask, and $5 \mathrm{ml} 50 \% \mathrm{NaOH}$ (mass fraction) solution was added. The mixture was completely agitated till uniformity, and irradiated for 5-6min in microwave oven (medium heat). After the reaction system was cooled to room temperature, the solution was adjusted by dilute hydrochloric acid to $\mathrm{pH} 1$. A large number of white precipitate occurred, the resultant solution was filtrated. The obtained filter cake was rinsed with a mass of water, and then recrystallized by ethanol/water. After drying, $7.9 \mathrm{~g}$ white solid compound 1a was obtained. $2.5 \mathrm{~g}$ compound 1 was dissolved in $10 \mathrm{ml}$ concentrated sulfuric acid, kept at room temperature for $12 \mathrm{~h}$ and then placed in the ice water bath for dissociation. Tremendous orange-yellow solid precipitation was obtained, and filtrated. Filter cake was rinsed by $5 \%$ sodium bicarbonate solution and water in order till neutral. The resultant crude produce was recrystallized with $50 \%$ ethanol, and $1.9 \mathrm{~g}$ orange solid compound $2 \mathrm{a}$ was obtained. The yield coefficient was $61 \%$ (counted by methyl thiophenol).

\subsection{Synthetic method of 3-bromine replaced thiochromanone (3)}

$2 \mathrm{~g}$ compound $2 \mathrm{a}$ was placed in $50 \mathrm{ml}$ round bottom flask and $6 \mathrm{ml}$ or so anhydrous ethanol was added. The mixture was placed in oil bath at $40^{\circ} \mathrm{C}$, and ethanol solution containing bromine $(1.2 \mathrm{ml} / 4 \mathrm{ml})$ was added in half an hour. The mixture system was stirred continuously, and tracked by TCL during the whole process. The reaction would be finished in about 3 hours. The reaction solution was added to $25 \mathrm{ml} 10 \%$ sodium bisulfite solution, and filtrated. Filter cake was rinsed by enormous water, and $2.6 \mathrm{~g}$ light yellow solid compound $3 \mathrm{a}$ was obtained after drying. The yield coefficient was about $91 \%$ (counted by thiochromanone).

\subsection{Synthetic method of 6H-thiochromeno [3, 4-b] quinoxaline}

$1 \mathrm{~g}(4 \mathrm{mmol}) 3$-Bromine 6-methyl thiochromanone 3a was placed in $50 \mathrm{ml}$ round bottom flask, and $0.55 \mathrm{~g}(5$ mmol) o-phenylenediamine and $2 \mathrm{ml}$ DMSO were added in order. The mixture was undertaken return flow agitation at $70^{\circ} \mathrm{C}$ oil bath (Wu, 2008, PP. 2132-2136). The whole process was tracked by TCL, and the reaction was finished in about an hour. The reaction solution was directly separated and purified by silica gel column chromatography, and ethyl acetate-petroleum (1:6) was applied as eluting agent. Light yellow solid compound 4a was obtained. The yield coefficient was $16 \%$ (counted by 3 -Bromine 6 -methyl thiochromanone). Compound $4 \mathrm{~b}$ was prepared in the same way. The synthesized target compounds and their structure were confirmed by HNMR and MS. The related data was listed in Table 1 in detail.

\subsection{Antifungal activity tests in vitro}

By agar double dilution method (plate method), firstly the tested compounds was dissolved by appropriate amount of DMSO, diluted by sterile distilled water, and added to sterile $1 \%$ glucose peptone medium. Sample concentration was $128,64,32,16,8$, and $44 \mu \mathrm{g} \cdot \mathrm{ml}-1$, respectively. Inoculated tested strains (a blank in each strain at the same time), was placed in incubators to cultivate for $5 \sim 7 \mathrm{~d}$. Using amphotericin B and fluconazole as a positive control, inhibitory effects were listed in Table 2 in detail.

\section{Results and discussions}

Antibacterial tests in vitro showed that: the target compounds had certain inhibitory effects on 8 species of fungi in vitro, and especially for t.rubrum, the inhibition effect was stronger. Among them, the minimum inhibitory concentration (MIC) of compound $4 \mathrm{a}$ and $4 \mathrm{~b}$ was all $4 \mu \mathrm{g} \cdot \mathrm{ml}-1$, and close to amphotericin B and fluconazole; the substituent R1 and R2 were more common in the state of electron-donating group than electron-withdrawing group, but its inhibitory concentration was not so good, furthermore, inhibitory effects of all compounds on fungi were not desirable.

Although antibacterial activities of $6 \mathrm{H}$-thiochromeno [3, 4-b] quinoxaline derivatives failed to approach to the MIC of patent medicine, as a new type parent ring structure, it could be undertaken further modification in order to obtain new compounds with better antibacterial activities.

\section{References}

Li, X., Yang, K.H., \& Qu, X.P., et al. (2007). Advances in the research of quinoxalinone derivatives. Chinese Journal of Medicinal Chemistry, 17(3):183-187.

Li, X., Yang, K.H., \& Qu, X.P., et al. (2007). Advances of biological quinoxalin compounds. Qilu Pharmaceutical Affairs, 26(1):34-36. 
Nakb, A.T., Bezjak, V., \& Meegan, M.J., et al. (1990). Synthesis and antifungal activity of some 32benzylidenechromanones.Eur J Med Chem, 25(5):455-462.

Qi, P., Le, Y.H., \& Guo, C., et al. (2004).Syntheses and the antifungal activity of 3-bromo-4-thiochrom (an) ones. Chinese Journal of Medicinal Chemistry, 13(3):134-137.

Qi, P., Le, Y.H., \& Guo, C., et al. (2004). Synthesis of 3-benzylthiochromanones and their in vitro antifungal activity. Chinese Journal of New Drugs, 13(2):141-143.

Tramontin, I.M., \& Angiolinil. (1990). Further advances in the chemistry of Mannich base.Tetrahedron, 46(6): 1791-1837.

Wu, H.W., \& Yang, G.S. (2008). One-pot synthesis of quinoxalines from $\alpha$-Haloketones and aromatic 1, 2-Diamines via an oxidation-condensation process. Chinese Journal of Organic Chemistry, 28(12):2132-2136.

Xiao, L.W., \& Li, H.Z. (2006). Synthesis of $\beta$-Arylthioethers of propionic acid and thiochromanones under microwave irradiation. Chinese Journal of Organic Chemistry, 26(7):979-982.

Table 1. Structure and spectrum data of target compounds

\begin{tabular}{|c|c|c|c|c|c|c|}
\hline Compounds & $\mathrm{R}_{1}$ & $\mathrm{R}_{2}$ & $\mathrm{mp} /{ }^{\circ} \mathrm{C}$ & Productivity $\%$ & ESI-MS(m/z) & ${ }^{1} \mathrm{H}-\mathrm{NMR}\left(\mathrm{CDCl}_{3}\right)$ ppm \\
\hline & $\mathrm{CH}_{3}$ & $\mathrm{~F}$ & $143-145^{\circ} \mathrm{C}$ & $91 \%$ & $195[\mathrm{M}+1]^{+}$ & $\begin{array}{l}2.30(\mathrm{~s}, 3 \mathrm{H}), 3.75-3.61(\mathrm{~m}, 1 \mathrm{H}) \\
3.48(\mathrm{td}, 1 \mathrm{H}), 4.95 \\
(\mathrm{dd}, \mathrm{J}=8.24,3.25 \mathrm{~Hz} 1 \mathrm{H}) \\
7.90-7.73(\mathrm{~m}, 1 \mathrm{H}), 7.17-7.11(\mathrm{~m}, \\
1 \mathrm{H})\end{array}$ \\
\hline $3 b$ & $\mathrm{Cl}$ & $\mathrm{Cl}$ & $116-118^{\circ} \mathrm{C}$ & $88 \%$ & $231[\mathrm{M}+1]^{+}$ & $\begin{array}{l}3.52-3.45(\mathrm{~m}, 1 \mathrm{H}), 3.74-3.68(\mathrm{~m}, \\
1 \mathrm{H}), 4.93 \\
(\mathrm{td}, 1 \mathrm{H}), 7.48-7.41(\mathrm{~m}, 1 \mathrm{H}) \\
8.29-8.13(\mathrm{~m}, 1 \mathrm{H})\end{array}$ \\
\hline $3 \mathrm{c}$ & $\mathrm{F}$ & $\mathrm{H}$ & $103-105^{\circ} \mathrm{C}$ & $92 \%$ & $181[\mathrm{M}+1]^{+}$ & $\begin{array}{l}3.50(\mathrm{dd}, 1 \mathrm{H}), 3.68(\mathrm{dd}, 1 \mathrm{H}), 4.98 \\
(\mathrm{dd}, 1 \mathrm{H}), 7.24-7.19(\mathrm{~m}, 1 \mathrm{H}), 7.30 \\
(\mathrm{dd}, 1 \mathrm{H}), 7.87(\mathrm{dd}, 1 \mathrm{H})\end{array}$ \\
\hline $3 d$ & $\mathrm{CH} 3$ & $\mathrm{H}$ & $57-58^{\circ} \mathrm{C}$ & $80 \%$ & $177[\mathrm{M}+1]^{+}$ & $\begin{array}{l}2.52-2.19(\mathrm{~s}, 3 \mathrm{H}), 3.50(\mathrm{dd}, 1 \mathrm{H}) \\
3.66(\mathrm{dd}, 1 \mathrm{H}), 4.98(\mathrm{dd}, 1 \mathrm{H}) \\
8.29-7.90(\mathrm{~m}, 1 \mathrm{H}), 7.21(\mathrm{~d}, \\
\mathrm{J}=8.09 \mathrm{~Hz} 1 \mathrm{H}), 7.31-7.28(\mathrm{~m}, 1 \mathrm{H})\end{array}$ \\
\hline $4 a$ & $\mathrm{CH} 3$ & $\mathrm{~F}$ & $163-166^{\circ} \mathrm{C}$ & $15 \%$ & $283[\mathrm{M}+1]^{+}$ & $\begin{array}{l}2.33(\mathrm{~s}, 3 \mathrm{H}), 4.28(\mathrm{~s}, 2 \mathrm{H}), 7.25 \\
(\mathrm{~d}, 1 \mathrm{H}), 8.20(\mathrm{~d}, 1 \mathrm{H}) \\
8.07-8.02(\mathrm{~m}, 2 \mathrm{H}), 8.13-8.10(\mathrm{~m}, \\
2 \mathrm{H})\end{array}$ \\
\hline $4 b$ & $\mathrm{Cl}$ & $\mathrm{Cl}$ & $151-153^{\circ} \mathrm{C}$ & $16 \%$ & $319[\mathrm{M}+1]^{+}$ & $\begin{array}{l}4.32(\mathrm{~s}, 2 \mathrm{H}), 8.68-8.61(\mathrm{~m}, 1 \mathrm{H}) \\
7.54(\mathrm{~s}, 1 \mathrm{H}), 7.79-7.76(\mathrm{~m}, 2 \mathrm{H}) \\
8.14(\mathrm{dd}, 1 \mathrm{H}), 8.06-8.03(\mathrm{~m}, 1 \mathrm{H})\end{array}$ \\
\hline $4 \mathrm{c}$ & $\mathrm{F}$ & $\mathrm{H}$ & $145-148^{\circ} \mathrm{C}$ & $17 \%$ & $269[\mathrm{M}+1]^{+}$ & $\begin{array}{l}4.31(\mathrm{~d}, 2 \mathrm{H}), 7.78-7.74(\mathrm{~m}, 2 \mathrm{H}) \\
7.12-7.08(\mathrm{~m}, 1 \mathrm{H}), 7.42-7.38(\mathrm{~m}, \\
1 \mathrm{H}), 8.29-8.24(\mathrm{~m}, 1 \mathrm{H}) \\
8.16-8.12(\mathrm{~m}, 1 \mathrm{H}), 8.06-8.01(\mathrm{~m}, \\
1 \mathrm{H})\end{array}$ \\
\hline $4 d$ & $\mathrm{CH} 3$ & $\mathrm{H}$ & $63-65^{\circ} \mathrm{C}$ & $13 \%$ & $265[\mathrm{M}+1]^{+}$ & $\begin{array}{l}2.58(\mathrm{~s}, 3 \mathrm{H}), 4.28(\mathrm{~d}, \\
2 \mathrm{H}), 7.84-7.80(\mathrm{~m}, 2 \mathrm{H}), 7.19-7.07 \\
(\mathrm{~m}, 2 \mathrm{H}), 8.42(\mathrm{~s}, 1 \mathrm{H}), 8.28 \\
(\mathrm{dd}, 1 \mathrm{H}), 8.16(\mathrm{dd}, \mathrm{J}=6.49,3.28 \mathrm{~Hz} \\
1 \mathrm{H})\end{array}$ \\
\hline
\end{tabular}


Table 2. Antifungal data of target compounds (MIC value, $\mu \mathrm{g} \cdot \mathrm{ml}-1$ )

\begin{tabular}{|c|c|c|c|c|c|c|c|c|}
\hline Compounds & $\begin{array}{l}\text { c. } \\
\text { tropicalis }\end{array}$ & $\begin{array}{l}c . \\
\text { parapsilosis }\end{array}$ & c.krusei & c.neoformans & t.rubrum & t.metagrophytes & $\begin{array}{l}\text { a. } \\
\text { fumigatus }\end{array}$ & a.niger \\
\hline $4 \mathrm{a}$ & 128 & 64 & 64 & 64 & 4 & 64 & 64 & - \\
\hline $4 b$ & - & 128 & 128 & 8 & 4 & 64 & - & - \\
\hline $4 \mathrm{c}$ & - & 32 & 128 & 32 & 32 & 64 & - & - \\
\hline $4 d$ & 128 & - & 128 & 32 & 64 & $\geq 128$ & 128 & 128 \\
\hline Amphotericin B & $2-4$ & $2-4$ & $1-4$ & $0.5-2$ & $2-4$ & 8-16 & $2-4$ & $0.5-1$ \\
\hline Fluconazole & $2-4$ & $0.5-2$ & - & $1-4$ & $2-4$ & $32-64$ & - & - \\
\hline
\end{tabular}

Note: “-” indicated no inhibitory activities
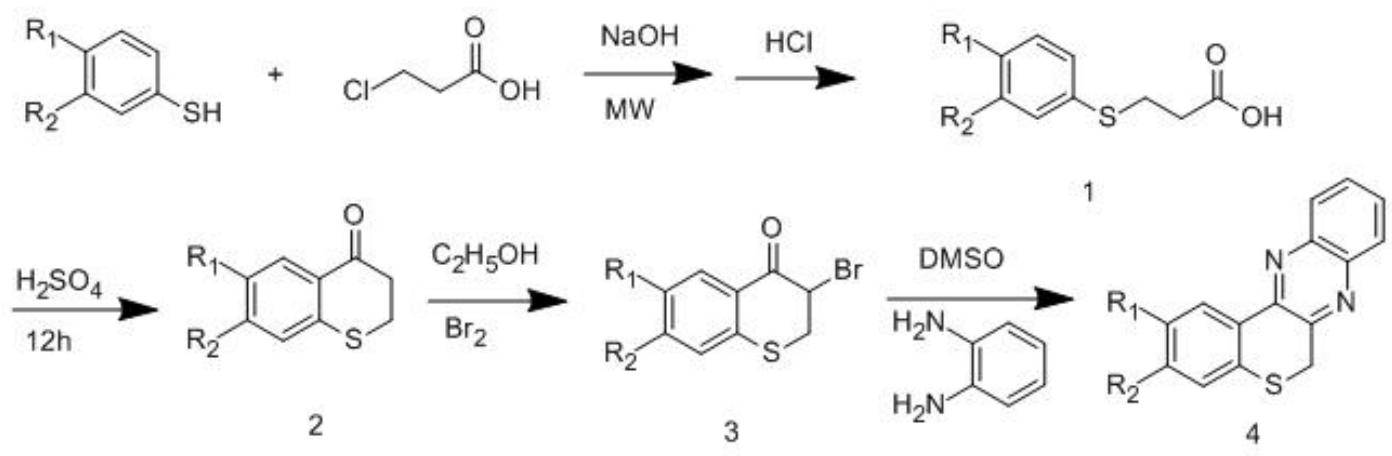

$$
\begin{aligned}
& 3 a: R_{1}=\mathrm{CH}_{3} \quad \mathrm{R}_{2}=\mathrm{F} \quad 3 \mathrm{~b}: \mathrm{R}_{1}=\mathrm{Cl} \quad \mathrm{R}_{2}=\mathrm{Cl} \quad 3 \mathrm{c}: \mathrm{R}_{1}=\mathrm{F} \quad \mathrm{R}_{2}=\mathrm{H} \quad 3 \mathrm{~d}: \mathrm{R}_{1}=\mathrm{CH}_{3} \quad \mathrm{R}_{2}=\mathrm{H} \\
& 4 \mathrm{a}: \mathrm{R}_{1}=\mathrm{CH}_{3} \quad \mathrm{R}_{2}=\mathrm{F} \quad 4 \mathrm{~b}: \mathrm{R}_{1}=\mathrm{Cl} \quad \mathrm{R}_{2}=\mathrm{Cl} \quad 4 \mathrm{c}: \mathrm{R}_{1}=\mathrm{F} \quad \mathrm{R}_{2}=\mathrm{H} \quad 4 \mathrm{~d}: \mathrm{R}_{1}=\mathrm{CH}_{3} \quad \mathrm{R}_{2}=\mathrm{H}
\end{aligned}
$$

Figure 1. Synthetic route of $6 \mathrm{H}$-thiochromeno [3, 4-b] quinoxaline derivatives 